\title{
Insulin response and changes in composition of non-esterified fatty acids in blood plasma of middle-aged men following isoenergetic fatty and carbohydrate breakfasts
}

\author{
D. L. Frape ${ }^{1,2 *}$, N. R. Williams ${ }^{2}$, K. L. H. Carpenter ${ }^{3}$, M. A. Freeman ${ }^{3}$, C. R. Palmer ${ }^{4}$ and R. J. Fletcher ${ }^{5}$ \\ ${ }^{1} N S$ Research, The Priory, Churchyard, Mildenhall, Suffolk IP28 7EE, UK \\ ${ }^{2}$ Pathology Department, Papworth Hospital, Cambridge CB3 8RE, UK \\ ${ }^{3}$ Department of Pathology, University of Cambridge, Tennis Court Road, Cambridge CB2 1QP, UK \\ ${ }^{4}$ Centre for Applied Medical Statistics, University of Cambridge, Robinson Way, Cambridge, CB2 2SR, UK \\ ${ }^{5}$ The Kellogg Company of Great Britain Ltd, The Kellogg Building, Talbot Road, Manchester M16 OPU, UK
}

(Received 29 October 1999 - Revised 13 March 2000 - Accepted 31 March 2000)

\begin{abstract}
It was previously shown that a high plasma concentration of non-esterified fatty acids (NEFA) persisted after a fatty breakfast, but not after an isoenergetic carbohydrate breakfast, adversely affecting glucose tolerance. The higher concentration after the fatty breakfast may in part have been a result of different mobilization rates of fatty acids. This factor can be investigated as NEFA mobilized from tissues are monounsaturated to a greater extent than those deposited from a typical meal. Twenty-four middle-aged healthy Caucasian men were given oral glucose tolerance tests (OGTT), and for $28 \mathrm{~d}$ isoenergetic breakfasts of similar fat composition but of low (L) or moderate (M) fat content. The composition of NEFA in fasting and postprandial plasma was determined on days 1 and 29. No significant treatment differences in fasting NEFA composition occurred on day 29. During the OGTT and $0-1 \mathrm{~h}$ following breakfast there was an increase in plasma long-chain saturated NEFA but a decrease in monounsaturated NEFA $(\mu \mathrm{g} /$ $100 \mu \mathrm{g}$ total NEFA; $P<0 \cdot 001)$. Between 1 and $3 \mathrm{~h}$ following breakfast treatment differences occurred for total saturated and total monounsaturated fatty acids $(\mu \mathrm{g} / 100 \mu \mathrm{g}$ total NEFA; $P<0.05)$, expressed as an increase in 18:1 and decreases in 16:0 and 17:0 in treatment M relative to treatment $\mathrm{L}(P<0 \cdot 05)$. Serum insulin attained 35 and $65 \mathrm{mU} / \mathrm{l}$ in treatments $\mathrm{M}$ and $L$ respectively during this period. Negative correlations were found between 16:0 in fasting plasma and both waist:hip circumference $(P=0.0009)$ and insulin response curve area during OGTT (within treatment $\mathrm{M}, P=0 \cdot 0001$ ). It is concluded that a normal postprandial insulin response is associated with a rapid change in plasma saturated:monounsaturated NEFA. It is proposed that this change is the result of a variable suppression of fat mobilization, which may partly account for a large difference in postprandial total plasma NEFA between fatty and carbohydrate meals.
\end{abstract}

Non-esterified fatty acids: Insulin: Dietary fat: Dietary carbohydrate

High circulating concentrations of non-esterified fatty acids (NEFA) have emerged as important risk factors for a variety of complex metabolic disorders. These disorders include non-insulin-dependent diabetes mellitus, dyslipidaemia, insulin resistance, hyperinsulinaemia and atherosclerotic cardiovascular disease (Frayn et al. 1997; Byrne et al. 1998). In a concentration-dependent manner NEFA decrease insulin binding and receptor-mediated insulin degradation in liver cells (Svedberg et al. 1990). The importance of elevated portal NEFA is supported by the observation that obese subjects, with high circulating NEFA concentrations, have fewer binding sites for insulin in the hepatocytes (Arner et al. 1986).

Chylomicrons are hydrolysed at the capillary endothelium by the action of lipoprotein lipase. This process causes a continuous influx of fatty acids into adipocytes. However,

\footnotetext{
Abbreviations: AUC, area under the curve; HSL, hormone-sensitive lipase; L, low-fat breakfast; M, moderate-fat breakfast; NEFA, non-esterified fatty acids; OGTT, oral glucose tolerance test; TAG, triacylglycerols.

* Corresponding author: Dr David Frape, fax +44 1638 712192, email david.1.frape@btinternet.com
} 
leak-back occurs, which augments the efflux entering the venous plasma as a result of the activity of intracellular hormone-sensitive lipase HSL. Thus, adipose tissue triacylglycerols (TAG) exist in a continuous dynamic state (Frayn, 1993). Following a fatty meal the influx greatly exceeds the efflux, as the efflux is suppressed by the action of insulin on HSL. Circulating NEFA are rapidly metabolized by other tissues, as they have a turnover of only a few minutes (Friderickson \& Gordon, 1958a,b). Consequently, they influence the availability of glucose by a fatty acid-mediated inhibition of plasma glucose clearance and cellular uptake in the insulin-stimulated state (Wolfe, 1998). We previously found that a relatively small increase in fat consumption from isoenergetic breakfasts was associated with a relatively large increase in plasma NEFA concentration that persisted for at least $5 \mathrm{~h}$. The NEFA were then associated with reduced glucose tolerance that was caused either by the breakfast on day 29 or by the effect of all breakfasts for days 1-29 (Frape et al. 1998).

Following consumption of a fatty meal containing $80 \mathrm{~g}$ fat and at least $80 \mathrm{~g}$ carbohydrate $(v .5 .5$ and $25.7 \mathrm{~g}$ fat and 113 and $56 \mathrm{~g}$ carbohydrate in the two meals in the present study) by healthy subjects, Griffiths et al. (1994) and Frayn et al. (1997) concluded that more than $80 \%$ of the venous NEFA draining adipose tissue were meal-derived through the activity of lipoprotein lipase. We questioned whether there may be an endogenous origin for a significant proportion of the raised postprandial NEFA following a moderately fatty breakfast. The origin of this NEFA may be elucidated by determining its fatty acid composition, and specifically the relative proportions of long-chain saturated and monounsaturated fatty acids. This procedure was previously adopted by Connor et al. (1996).

It was surmised that the difference between treatments in the carbohydrate content of the isoenergetic breakfasts, and the resulting insulin responses, would have been closely associated with a difference in the composition of postprandial NEFA in middle-aged men. This composition was now determined in an endeavour to understand the large treatment difference in plasma total NEFA concentration. Evidence from experiments on rabbits indicates that mobilized endogenous fatty acids are considerably less saturated than the fatty acids of adipose tissue sources from which they originate (Connor et al. 1996). Insulin response associated with insulin resistance, or the consumption of a low-carbohydrate meal, may fail to adequately suppress postprandial intracellular fat mobilization. Consequently, monounsaturated fatty acids, as a proportion of total plasma NEFA, should not decrease to the extent that they may do following a carbohydrate meal.

\section{Experimental methods}

\section{Subjects and diets}

Full details of design, procedures, statistical methods and composition of the test meals have been reported previously (Frape et al. 1998). Twenty-four middle-aged non-smoking healthy Caucasian men aged 35-65 years (Table 1) were given low-fat ( $\mathrm{L}$; composed of $86 \mathrm{~g}$ corn
Table 1. Characteristics of the twenty-four male subjects on day 1 (Values are means and their standard deviations for twelve subjects)

\begin{tabular}{|c|c|c|c|c|}
\hline \multirow[t]{2}{*}{ Treatment group... } & \multicolumn{2}{|c|}{$\mathrm{L}$} & \multicolumn{2}{|c|}{ M } \\
\hline & Mean & SD & Mean & SD \\
\hline Age (years) & $48 \cdot 1$ & $8 \cdot 2$ & $50 \cdot 6$ & 8.0 \\
\hline Weight (kg) & $79 \cdot 7$ & $6 \cdot 5$ & $80 \cdot 3$ & $7 \cdot 9$ \\
\hline $\operatorname{BMI}\left(\mathrm{kg} / \mathrm{m}^{2}\right)$ & $26 \cdot 8$ & $2 \cdot 7$ & $25 \cdot 2$ & 2.5 \\
\hline Waist:hip circumference & 0.900 & 0.038 & 0.901 & 0.0 \\
\hline \multicolumn{5}{|l|}{ Fasting blood values } \\
\hline Insulin (mU/l) & $6 \cdot 55$ & $6 \cdot 43^{*}$ & $8 \cdot 65$ & $3 \cdot 78^{*}$ \\
\hline Glucose (mmol/l) & $5 \cdot 10$ & 0.58 & 4.98 & 0.42 \\
\hline TAG $(\mathrm{mmol} / \mathrm{l})$ & 1.30 & $1 \cdot 17$ & 1.32 & 0.73 \\
\hline NEFA (mmol/l) & 0.47 & 0.31 & 0.41 & 0.11 \\
\hline Total cholesterol $(\mathrm{mmol} / \mathrm{l})$ & $5 \cdot 69$ & 1.41 & $5 \cdot 85$ & 1.08 \\
\hline LDL-cholesterol (mmol/l) & 3.83 & $1 \cdot 17$ & 3.97 & 0.80 \\
\hline \multicolumn{5}{|c|}{ Areas under the curve during OGTT } \\
\hline Glucose (mmol/l.min) & $824 \cdot 8$ & 195 & $739 \cdot 3$ & 99 \\
\hline TAG $(m$ & $158 \cdot 2$ & 132 & $160 \cdot 1$ & 87 \\
\hline NEFA (mmol/l.min) & $24 \cdot 6$ & 17 & $23 \cdot 0$ & 13 \\
\hline
\end{tabular}

L, low-fat breakfast; M, moderate-fat breakfast; TAG, triacylglycerols; NEFA, non-esterified fatty acids; OGTT, oral glucose tolerance test.

* Median and interquartile range.

flakes $+300 \mathrm{ml}$ semi-skimmed milk $+250 \mathrm{ml}$ orange juice, providing $5.5 \mathrm{~g}$ fat and $113 \mathrm{~g}$ carbohydrate), or moderately fatty (M; a pastie weighing $86 \mathrm{~g}$, composed of a lean meatvegetable mixture in a pastry covering, in which the fat was predominately butter, individually prepared by Country \& Colonial, 18300 Ménétréol-sous-Sancerre, France and providing $26 \mathrm{~g}$ fat and $56 \mathrm{~g}$ carbohydrate) isoenergetic breakfasts for $28 \mathrm{~d}$ with control over the other two daily meals (Frape et al. 1998). The fatty acid composition of the two breakfast menus (Table 2) was determined by a GC method of Medina et al. (1992).

There were twelve pairs of men matched according to the characteristic: waist:hip circumference $\times$ fasting LDLcholesterol. The two dietary treatments were allocated at random within pairs. The treatment breakfasts were each taken with a cup of tea or coffee on days 2-28 at home before 09.00 hours. Tea and coffee were not given on day 29. All subjects were provided with a low-fat cereal evening meal that was eaten exclusively at 19.00 hours on days 0 and 28. Subjects were then fasted until 09.00 hours on days 1 and 29. On days 2-28, some freedom was given in the composition of the two other daily meals taken at midday and in the evening. The content of these meals was recorded daily by each subject in a diary. High-fat foods were avoided, fish was excluded and all meals were taken at home. No subject received prescription drug treatment or took any drug containing salicylic acid or sodium salicylate during the course of the study.

On day 1 fasting blood characteristics were measured and all subjects were given an oral glucose tolerance test (OGTT) at 09.00 hours. The glucose load was $66 \mathrm{~g}$ glucose monohydrate $(60 \mathrm{~g}$ glucose $)$ in approximately $400 \mathrm{ml}$ water. On day 29 each subject received their previously allocated L or M breakfast at 09.00 hours, followed at 13.30 hours by an OGTT. Water was available for drinking on both days 1 and 29. All test meals and metabolic measurements were carried out in Papworth Hospital and were synchronized within pairs on days 1 and 29.

Body weight, height and waist and hip circumferences 
Table 2. Fatty acid compositions ( $\mu \mathrm{g} / 100 \mu \mathrm{g}$ total fatty acids) of the breakfast meals and the fasting plasma triacylglycerols (TAG) and non-esterified fatty acids (NEFA) for healthy middle-aged men on day 29 of the study ${ }^{*} \dagger$

(Plasma values are means with their standard errors for twelve subjects)

\begin{tabular}{|c|c|c|c|c|c|c|c|c|c|c|}
\hline & & & \multicolumn{4}{|c|}{ TAG } & \multicolumn{4}{|c|}{ NEFA } \\
\hline & \multicolumn{2}{|c|}{ Meal } & \multicolumn{2}{|c|}{ L } & \multicolumn{2}{|c|}{ M } & \multicolumn{2}{|c|}{$L$} & \multicolumn{2}{|c|}{$M$} \\
\hline & L & M & Mean & SEM & Mean & SEM & Mean & SEM & Mean & SEM \\
\hline $14: 0$ & 8.7 & 9.1 & $2 \cdot 0$ & 0.23 & $2 \cdot 3$ & 0.21 & 3.0 & 0.29 & $2 \cdot 7$ & 0.24 \\
\hline $16: 0$ & 24.4 & $25 \cdot 1$ & $30 \cdot 6$ & 0.82 & $28 \cdot 6$ & 1.01 & 32.7 & 1.09 & 30.9 & 0.88 \\
\hline $16: 1$ & $2 \cdot 3$ & 3.1 & 3.2 & 0.27 & 3.8 & 0.38 & 2.4 & 0.20 & 3.4 & 0.48 \\
\hline $17: 0$ & 0 & 1.3 & 0.4 & 0.10 & 0.4 & 0.08 & 0.8 & 0.09 & 0.8 & 0.06 \\
\hline $18: 0$ & 9.6 & $12 \cdot 2$ & $5 \cdot 1$ & 0.58 & 6.1 & 1.12 & 16.5 & 1.09 & 16.0 & 1.01 \\
\hline $18: 1$ & 29.6 & $29 \cdot 3$ & $42 \cdot 8$ & 1.56 & $42 \cdot 2$ & 1.93 & 31.9 & 1.50 & 33.4 & 1.52 \\
\hline $18: 2$ & 12.2 & $5 \cdot 3$ & $14 \cdot 7$ & $1 \cdot 26$ & $15 \cdot 2$ & 1.39 & $12 \cdot 1$ & $1 \cdot 12$ & $12 \cdot 2$ & 1.05 \\
\hline $20: 4$ & 0 & 0.3 & 0.7 & 0.11 & 0.9 & 0.18 & 0.5 & 0.16 & 0.4 & 0.09 \\
\hline $22: 6$ & 0 & 0.1 & 0.4 & 0.09 & 0.4 & 0.04 & 0.1 & 0.04 & 0.1 & 0.05 \\
\hline
\end{tabular}

L, low-fat breakfast; M, moderate-fat breakfast

${ }^{*}$ For details of subjects and procedures, see Table 1 and p. 738.

$\dagger$ There were no significant differences between treatments for any fatty acid: $P>0.05$.

(measured at the levels of the umbilicus and the greater trochanter of the femur respectively) were recorded in fasting subjects by the same nurse at the same time of day during the medical examination on days 1 and 29 . Waist:hip circumference varied from 0.80 to 1.05 . Comparisons between treatments were made over the entire response period, but particularly 12.00 hours on day 29, at which time it was previously found (Frape et al. 1998) that total plasma NEFA values differed between treatments to the greatest extent. The null hypothesis was that the fatty acid profile of the NEFA would be the same for the two treatments, as the dietary fats had a similar fatty acid composition (Table 2). Blood was sampled repeatedly following both the OGTT and meals. The procedures for the withdrawal and preparation of blood samples, and the measurement of total NEFA content of the samples have been described previously by Frape et al. (1997).

\section{Analytical procedure}

The plasma samples for the fatty acid analyses were held at $-70^{\circ} \mathrm{C}$ before analysis. The fatty acid composition $(\mu \mathrm{g} /$ $100 \mu \mathrm{g}$ ) of the NEFA and fasting TAG samples was determined by GC after preparative TLC (one subject per plate) of the plasma lipids extracted by a modification of the procedure of Bligh \& Dyer (1959). All reagents were analytical grade; in addition, chloroform and diethyl ether were further purified by redistillation. Water was glass distilled. Analytical processing was carried out in Decon 90 (BDH, Poole, Dorset, UK)-cleaned chloroform-rinsed glass tubes. TLC plates were cleaned by pre-elution with solvent mixture of the composition to be used for chromatography, then air-dried at room temperature before application of samples. Plasma $(200 \mu \mathrm{l})$ was added to $4 \mathrm{ml}$ saline $(0.9 \%$ $\mathrm{NaCl}, \mathrm{w} / \mathrm{v}$ ), which was then acidified (using a few drops of $1 \mathrm{M}-\mathrm{HCl}$ ) to $\mathrm{pH} 4 \cdot 0-4 \cdot 5$. Methanol (10 ml) and chloroform $(5 \mathrm{ml})$ were added, and the mixture was mixed thoroughly. A further $5 \mathrm{ml}$ saline and $5 \mathrm{ml}$ chloroform were then added, vortexed and centrifuged (1500 rpm, $4^{\circ} \mathrm{C}, 10 \mathrm{~min}$ ).
The upper aqueous layer was removed by aspiration and the lower chloroform layer containing the lipids was collected and evaporated to dryness under a gentle stream of $\mathrm{O}_{2}$-free $\mathrm{N}_{2}$. The dry sample was redissolved in a small volume of chloroform (approximately $100 \mu \mathrm{l}$ ) for TLC using Whatman TLC plates $(20 \mathrm{~cm} \times 20 \mathrm{~cm} \times 1000 \mu \mathrm{m}$, Type code PK6F silica gel $60 \mathrm{~A}^{\circ}$; Whatman International Ltd., Maidstone, Kent, UK). The plates were developed in hexane-chloroform-diethyl ether-glacial acetic acid (120:15:15:1.5, by vol.) The NEFA and TAG bands $\left(\mathrm{R}_{\mathrm{f}}\right.$ values of 0.28 and 0.45 respectively) were identified in u.v. light and scraped into glass tubes. The samples were extracted with chloroform, evaporated under Ar and stored at $-70^{\circ} \mathrm{C}$ in screw-capped vials. The TAG were hydrolysed overnight under $\mathrm{N}_{2}$ in the dark at room temperature, using $3 \mathrm{ml}$ of a solution containing $1 \mathrm{~g} \mathrm{KOH}, 10 \mathrm{ml}$ diethyl ether, $10 \mathrm{ml}$ methanol, $2 \mathrm{ml}$ water. Water $(1 \mathrm{ml})$ was added and the samples were acidified with $3 \mathrm{M}-\mathrm{HCl}$ and extracted twice with $3 \mathrm{ml}$ diethyl ether. The diethyl ether extracts were washed with water, and evaporated under a stream of $\mathrm{N}_{2}$. The samples were redissolved in $2 \mathrm{ml}$ dichloromethane and transferred to screw-capped vials, in which they were stored under $\mathrm{Ar}$ at $-70^{\circ} \mathrm{C}$. Before derivatization the samples were evaporated to dryness under a gentle stream of $\mathrm{N}_{2}$. A few drops of methanol were then added to both the NEFA and the TAG hydrolysate samples, followed by $1 \mathrm{ml}$ freshly prepared diazomethane (solution in diethyl ether) to convert the fatty acids to their methyl esters. After $10 \mathrm{~min}$ the excess diazomethane was evaporated under a gentle stream of $\mathrm{N}_{2}$ and the fatty acid methyl esters redissolved in hexane and stored at $-20^{\circ} \mathrm{C}$ under Ar before GC analysis. GC was carried using a Vega 6130 gas chromatograph (Carlo Erba Instruments, Milan, Italy), with a $30 \mathrm{~m} \mathrm{DB}-1$ fused silica capillary column (i.d. $0.32 \mathrm{~mm}$ and film thickness 0.1 $\mu \mathrm{m}$; J\&W Scientific, Folsom, CA, USA). The temperature was programmed to increase from 50 to $120^{\circ} \mathrm{C}$ at $10^{\circ} \mathrm{C} / \mathrm{min}$, from 120 to $200^{\circ} \mathrm{C}$ at $4^{\circ} \mathrm{C} / \mathrm{min}$, from 200 to $280^{\circ} \mathrm{C}$ at $3^{\circ} \mathrm{C} / \mathrm{min}$, and then at $280^{\circ} \mathrm{C}$ for $10 \mathrm{~min} . \mathrm{H}_{2}$ carrier gas was used at an inlet pressure of $80 \mathrm{kPa}$. A $2 \mu \mathrm{l}$ portion of each sample was injected using an AS800 autosampler (Carlo Erba Instruments) via a split-splitless injector operated in the splitless mode. Detection was by a flame-ionization detector, and the output recorded using a DP800 integrator (Carlo Erba Instruments). The injector and detector temperatures were 270 and $280^{\circ} \mathrm{C}$ respectively.

Identification of peaks was achieved by GC retention times with reference to authentic standards, and by GCMS. The retention times, areas and peak heights of the predominant fatty acid peaks were recorded. Each peak was expressed both as a percentage $(\mu \mathrm{g} / 100 \mu \mathrm{g})$ of the total area and height of all the predominant and identified peaks, and in $\mu \mathrm{g} / \mathrm{l}$ plasma, for two blood sampling times on day 1 and five sampling times on day 29.

\section{Statistical analysis}

Responses for all repeated measurement variables were summarized at individual subject level. Variables not normally distributed were $\log _{\mathrm{e}}$-transformed towards normality. The responses from fasting of total saturated and 
monounsaturated acids, and 16:0/18:1, were analysed separately by ANOVA. Time means for individual fatty acids were compared by $t$ test, where ANOVA indicated a significant treatment effect. Areas under the curve (AUC) and incremental areas from the baseline were calculated by applying the trapezium rule to time points (Altman, 1991). Statistical significance was accepted at $P<0 \cdot 05$. Standard errors of the mean indicate the variation within treatment. The Pearson correlation coefficient was employed to assess associations. All comparisons were carried out with SPSS for Windows version 9.0 (SPSS Inc., Chicago, IL, USA) and, where appropriate, by Microsoft Excel 97 for Windows software (Microsoft Corporation, Seattle, WA, USA).

\section{Ethical considerations}

The protocol for the experiment was approved by the Huntingdon Area Medical Ethics Committee, and all subjects gave informed written consent to participate. The investigations were carried out in accordance with the principles of the Declaration of Helsinki.

\section{Results}

\section{Fatty acid comparisons}

We compared long-chain saturated $\left(\mathrm{C}_{14}, \mathrm{C}_{16}, \mathrm{C}_{17}\right.$ and $\left.\mathrm{C}_{18}\right)$ and monounsaturated $\left(\mathrm{C}_{16}\right.$ and $\left.\mathrm{C}_{18}\right)$ fatty acids, constituting $89.9 \%$ of the total measured fatty acids of plasma NEFA during the OGTT and during the postprandial period following breakfast. All plasma values given in tables and figures represent the means of twelve subjects. The fatty acid compositions of the two breakfast meals given at 09.00 hours on days 1-29 were very similar, and are shown in Table 2. Neither the fatty acid composition of the fasting plasma NEFA nor that of the fasting plasma TAG measured either as $\mu \mathrm{g} / 100 \mu \mathrm{g}$ total fatty acids or as $\mu \mathrm{g} / \mathrm{l}$ plasma, differed significantly between treatments on day 29 (Table $2 ; \mu \mathrm{g} / \mathrm{l}$ plasma values are not shown).

We have demonstrated previously (Frape et al. 1998) that the difference between treatments $\mathrm{L}$ and $\mathrm{M}$ on day 29 with regard to total NEFA content of plasma reached a maximum at 12.00 hours, $3 \mathrm{~h}$ following the meal. Furthermore, over the period 09.00-13.20 hours, the NEFA AUC with treatment L was only $59 \%$ of that with treatment $\mathrm{M}$. In the present study, long-chain saturated fatty acids were examined separately from monounsaturated fatty acids. ANOVA indicated significant treatment differences over the postprandial period following breakfast on day 29 for total saturated $(P=0.027)$ and total monounsaturated $(P=0.0026)$ fatty acids expressed as $\mu \mathrm{g} /$ $100 \mu \mathrm{g}$ NEFA. The responses at 10.00 hours did not differ significantly from those at 12.00 hours. The values for individual fatty acids at 12.00 hours are given in Fig. 1.

The insulin responses during the OGTT on days 1 and 29 were considerable with both treatments (see p. 741) and so differences were not expected in the associated responses of any fatty acid to the OGTT over $120 \mathrm{~min}$. This was the case and so the values for the two treatments and for days 1 and 29 were combined (Table 3). The proportion of the saturated fatty acids increased and that of monounsaturated fatty acids decreased following the oral glucose dose $(P<0.002)$. This response was in accordance with that observed $1 \mathrm{~h}$ after consumption of the breakfast meal for both treatments (Table 4; Fig. 2 for monounsaturated fatty acids). Saturated fatty acids gave a fractional response which was approximately $1-x$ (data not shown) of the monounsaturated fatty acid response (x). At $1 \mathrm{~h}$ after the meal the fatty acid composition of the NEFA for the two treatments, L and M, diverged. At 12.00 hours, $3 \mathrm{~h}$ after the treatment $\mathrm{L}$ meal, the proportions of $16: 0$ and $17: 0$ were greater $(P=0.026$ and 0.0055 respectively) and that of $18: 1$ was lower $(P=$ 0.0027) than those for treatment M (Fig. 1).

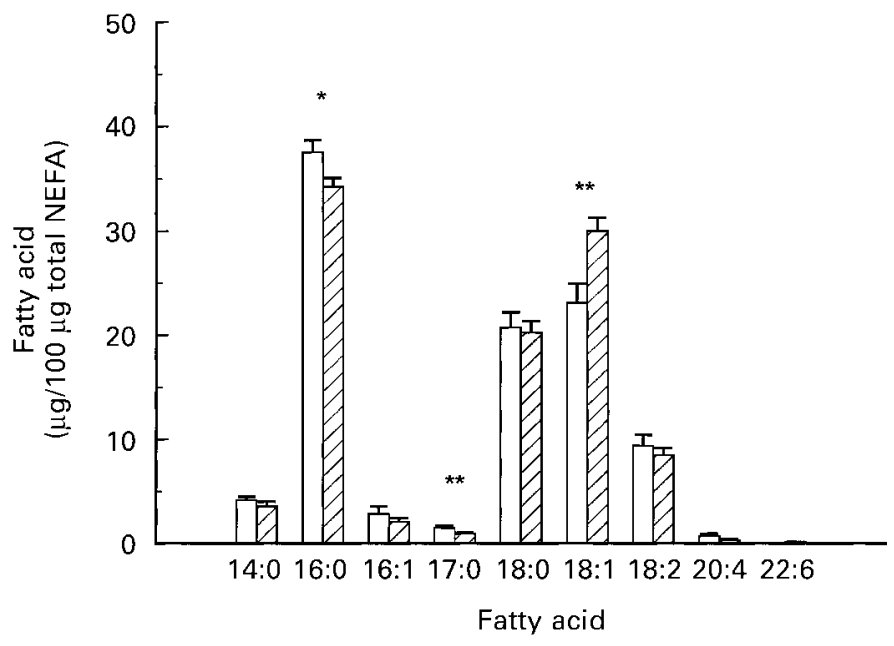

Fig. 1. Non-esterified fatty acid (NEFA) composition of plasma ( $\mu \mathrm{g} /$ $100 \mu \mathrm{g}$ total NEFA) in healthy middle-aged men at 12.00 hours, $3 \mathrm{~h}$ after consumption of either a low-fat $(\mathrm{L} ; \square)$ or moderate-fat $(\mathrm{M} ; \mathbb{Z})$ breakfast meal on day 29. For details of the breakfast meals and procedures, see Table 2 and p. 738. Values are means with their standard errors represented by vertical bars for twelve subjects. Mean values were significantly different between treatments: ${ }^{*} P<0.05,{ }^{\star \star} P<0.01$. 
Table 3. Plasma non-esterified fatty acids ( $\mu \mathrm{g} / 100 \mu \mathrm{g}$ total non-esterified fatty acids) in healthy middleaged men before and $120 \mathrm{~min}$ after a $60 \mathrm{~g}$ oral glucose dose*

(Values are means with their standard errors for twenty-four subjects)

\begin{tabular}{|c|c|c|c|c|c|}
\hline \multirow[b]{2}{*}{ Fatty acid } & \multicolumn{2}{|c|}{ Pre-dose† } & \multicolumn{2}{|c|}{ Post-dose† } & \multirow{2}{*}{$\begin{array}{l}\text { Statistical significance of } \\
\text { difference between means: } P\end{array}$} \\
\hline & Mean & SEM & Mean & SEM & \\
\hline $14: 0$ & $3 \cdot 27$ & 0.17 & 4.46 & 0.34 & $<0.0001$ \\
\hline $16: 0$ & $32 \cdot 16$ & 0.53 & 35.40 & 0.85 & $<0.0001$ \\
\hline $16: 1$ & 2.63 & 0.23 & $2 \cdot 16$ & 0.16 & 0.002 \\
\hline $17: 0$ & 0.76 & 0.07 & 1.20 & 0.13 & 0.0002 \\
\hline $18: 0$ & 14.82 & 0.79 & 20.03 & 0.90 & $<0.0001$ \\
\hline $18: 1$ & 33.49 & 1.03 & 25.04 & 1.04 & $<0.0001$ \\
\hline $18: 2$ & $12 \cdot 27$ & 0.83 & $10 \cdot 82$ & 0.98 & 0.054 \\
\hline $20: 4$ & 0.35 & 0.05 & 0.67 & 0.18 & 0.04 \\
\hline
\end{tabular}

* For details of procedures, see p. 738.

† Values are pooled from both treatment groups and from days 1 and 29 as individual values did not differ significantly.

\section{Insulin response}

Before treatment allocation there was no significant difference in the plasma insulin response to an oral glucose dose on day 1 . However, there were significant differences between treatments in the plasma insulin response to the breakfast (incremental $\log _{\mathrm{e}}$ AUC, $P=0.051$ ) and to the oral glucose dose $\left(\log _{\mathrm{e}}\right.$ AUC, $\left.P=0.038\right)$ on day 29 . On day 29, comparisons between treatments at 10.00 $(P=0.014), 14.30(P=0.062)$ and $15.00(P=0.024)$ hours indicated differences in insulin response $\left(\log _{\mathrm{e}} \mathrm{mU} / \mathrm{l}\right)$ (Fig. 3).

\section{$16: 0 / 18: 1$ response}

From fasting to 13.30 hours on day 29 , the $16: 0 / 18: 1$ plasma values indicated a difference in response between treatments $(P<0.01)$. From fasting to $3 \mathrm{~h}$ after the breakfast, this ratio increased from 1.06 (SE 0.084) to 1.78 (SE 0.214) for treatment L (a $67 \%$ increase), but it increased by only $23 \%$ from 0.95 (SE 0.064 ) to 1.17 (SE 0.068 ) for treatment M (Fig. 4). Adipose tissue fat has been reported to have a mean $16: 0 / 18: 1$ of 0.49 (range 0.460.56; Heffernan, 1963; Brook, 1971; Kokatnur et al. 1979; Pittet et al. 1979; Malcom et al. 1989), compared with the corresponding values for the fat in meals of 0.83 for $\mathrm{L}$ and 0.86 for $\mathrm{M}$. The plasma ratio for treatment $\mathrm{M}$ was closer to that for adipose tissue fat and less than that for treatment $\mathrm{L}$ at 12.00 hours $(P=0 \cdot 012)$. At 13.30 hours serum insulin had returned to fasting concentrations, at which time the saturated and monounsaturated fatty acid profiles were very similar between treatments. The subsequent increases in 16:0/18:0 during the OGTT were from 1.00 (SE 0.037) to 1.62 (SE 0.175) for treatment $\mathrm{L}$ and from 1.03 (SE 0.046) to 1.66 (SE 0.151 ) for treatment $\mathrm{M}$. These increases were similar to those for treatment L after the breakfast (Fig. 4).

\section{Associations between 16:0 and insulin and between 16:0 and waist:hip circumference}

16: 0 represented a major fraction of the NEFA, especially during the insulin response to digestible carbohydrate. It was expected that its concentration $(\mu \mathrm{g} / 100 \mu \mathrm{g}$ total NEFA) would be negatively correlated, especially within treatment $\mathrm{M}$, to insulin AUC response after the breakfast meal. 16:0 was correlated with the contemporary plasma $\log _{\mathrm{e}}$ insulin AUC $(r-0.47, P=0.02)$ at 11.00 hours on day 1 , before treatment allocation, during the OGTT. At 12.00 hours on day 29 , following the meal, the correlation of plasma 16:0 with the contemporary $\log _{\mathrm{e}}$ insulin AUC was stronger within treatment $\mathrm{M}(r-0.91, P=0.0001)$ than within treatment $\mathrm{L}(r-0.52, P=0.08)$. For times 10.00 and 12.00 hours combined, the corresponding values

Table 4. Plasma non-esterified fatty acids ( $\mu \mathrm{g} / 100 \mu \mathrm{g}$ total non-esterified fatty acids) in healthy middle-aged men immediately before (09.00 hours) and $1 \mathrm{~h}$ after (10.00 hours) consumption of a low-fat $(\mathrm{L})$ or moderate-fat (M) breakfast meal on day $29^{*}$

(Values are means with their standard errors for twelve subjects)

\begin{tabular}{|c|c|c|c|c|c|c|c|c|c|c|}
\hline \multirow[t]{3}{*}{ Treatment group... } & \multicolumn{4}{|c|}{ L } & \multirow{3}{*}{$\begin{array}{c}\text { Statistical significance } \\
\text { of difference between } \\
\text { means: } P=\end{array}$} & \multicolumn{4}{|c|}{$\mathrm{M}$} & \multirow{3}{*}{$\begin{array}{c}\text { Statistical significance } \\
\text { of difference between } \\
\text { means: } P=\end{array}$} \\
\hline & \multicolumn{2}{|c|}{09.00 hours } & \multicolumn{2}{|c|}{10.00 hours } & & \multicolumn{2}{|c|}{09.00 hours } & \multicolumn{2}{|c|}{10.00 hours } & \\
\hline & Mean & SEM & Mean & SEM & & Mean & SEM & Mean & SEM & \\
\hline $14: 0$ & 2.97 & 0.29 & $4 \cdot 14$ & 0.34 & 0.008 & 2.69 & 0.24 & 3.60 & 0.27 & 0.003 \\
\hline $16: 0$ & 32.69 & 1.09 & 36.23 & 1.61 & 0.013 & 30.93 & 0.88 & 33.59 & 0.94 & 0.018 \\
\hline $16: 1$ & 2.43 & 0.20 & 1.94 & 0.18 & 0.040 & 3.40 & 0.48 & $2 \cdot 37$ & 0.24 & 0.007 \\
\hline $17: 0$ & 0.84 & 0.09 & $1 \cdot 11$ & 0.20 & 0.130 & 0.81 & 0.06 & 1.05 & 0.09 & 0.010 \\
\hline $18: 0$ & 16.52 & 1.09 & 21.21 & 1.36 & 0.0003 & 16.01 & 1.01 & 19.28 & 1.31 & 0.058 \\
\hline $18: 1$ & 31.89 & 1.50 & 24.76 & 1.82 & 0.0003 & 33.4 & 1.52 & $29 \cdot 17$ & 1.50 & 0.022 \\
\hline $18: 2$ & $12 \cdot 10$ & $1 \cdot 12$ & 9.84 & 1.47 & 0.027 & $12 \cdot 21$ & 1.05 & 10.02 & 0.80 & 0.017 \\
\hline $20: 4$ & 0.48 & 0.16 & 0.61 & 0.14 & 0.320 & 0.43 & 0.09 & 0.66 & 0.13 & 0.120 \\
\hline
\end{tabular}

\footnotetext{
* For details of breakfast meals and procedures, see Table 2 and p. 738.
} 

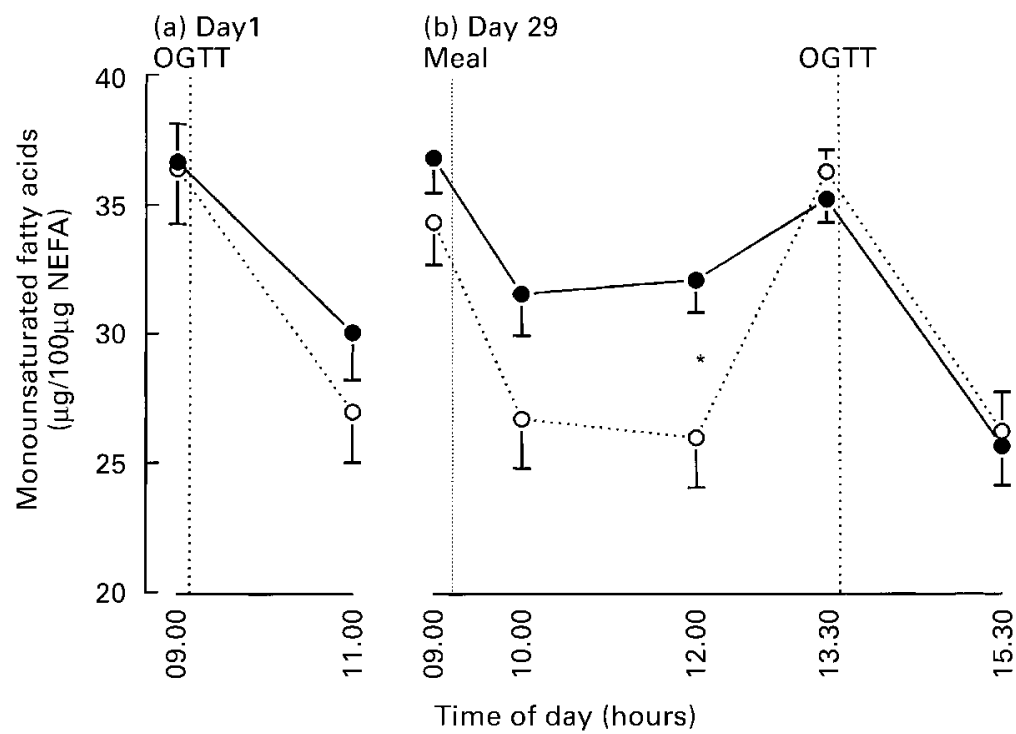

Fig. 2. Monounsaturated (16:1+18:1) non-esterified fatty acid (NEFA) composition of plasma $(\mu \mathrm{g} / 100 \mu \mathrm{g}$ total NEFA) in healthy middle-aged men before (day 1 ; a) and after (day 29; b) consuming a low-fat $(\mathrm{L} ; \mathrm{O})$ or moderate-fat $(\mathrm{M} ; \bullet)$ breakfast meal for $28 \mathrm{~d}$. Fasting fatty acid compositions are shown at 09.00 hours on both days. An oral glucose dose was given at 09.00 hours on day 1 and at 13.30 hours on day 29. The breakfast meal was consumed at 09.00 hours on day 29. For details of the breakfast meals and procedures, see Table 2 and p. 738. Values are means with their standard errors represented by vertical bars for twelve subjects. The change in plasma monounsaturated fatty acid compositions from fasting to 13.30 hours on day 29 was significantly different between treatments $(P=0.0026)$. Mean values were significantly different between treatments within times: ${ }^{*} P<0.05$. Saturated fatty acids $\left(\mathrm{C}_{14}+\mathrm{C}_{16}+\mathrm{C}_{17}+\mathrm{C}_{18}\right)$ gave a fractional response which was approximately $1-x$ (data not shown) of the monounsaturated fatty acids response (x). OGTT, oral glucose tolerance test.

were $r-0.79, P=0.002$ and $r-0.57, P=0.051$ for treatments $\mathrm{M}$ and $\mathrm{L}$ respectively.

Intra-abdominal fat is subject to a high flux (Arner, 1995). A high waist:hip circumference should therefore be associated with a relatively higher proportion of $18: 1$ and a lower proportion of 16:0 ( $\mu \mathrm{g} / 100 \mu \mathrm{g}$ plasma total NEFA), especially when plasma insulin is at post-absorptive concentrations (Arner, 1995). Indeed, we found that fasting $16: 0$ on day 1 was correlated with waist:hip circumference on day $1, r-0.63, P=0.0009$ (principally an effect of differences in waist measurement; $r-0.57, P=0.003$ ), whereas the corresponding values for $18: 1$ were $r 0.43$, $P=0 \cdot 04$.

\section{Discussion}

The saturated and monounsaturated fatty acid composition of NEFA is the result of: (1) different individual mobilization rates of fatty acids by HSL (Connor et al. 1996); (2) the composition and extent of leak-back of fatty acids from lipoprotein lipase activity (Fielding \& Frayn, 1998); (3) differential clearance rates, (not differentiated in our data). Nevertheless, our two diets had very similar fatty acid compositions, and plasma TAG concentrations, of low chylomicron content, did not differ significantly between treatments throughout day 29 (Frape et al.1998). Leak-back composition should not have been very different between treatments, and the composition of fasting plasma TAG and
NEFA, and the fasting insulin were all very similar between treatments (Table 2 and Fig. 3). Turn-over rates of isotopically-labelled 16:0 and 18:1 were found to be similar (Friderickson \& Gordon $1958 a, b$ ), as were the rates of ${ }^{13} \mathrm{CO}_{2}$ recovery in breath of absorbed labelled $16: 0$ and 18: 1 (Jones et al. 1999). Thus, disposal rates of these two predominant circulating fatty acids are similar. Although an influence in our data from leak-back and clearance cannot be excluded, a large difference in the tendency of individual fatty acids to be mobilized has been reported (see p. 742).

\section{Mobilization of tissue fatty acids}

HSL activity is inhibited in healthy young subjects when plasma insulin concentration exceeds 13-16 mU/l (Frayn et al. 1997). Nevertheless, there is a dose-response relationship between serum insulin concentration and the postprandial appearance of plasma fatty acids, a relationship that is more pronounced in middle-aged and obese subjects. A small increment in plasma insulin concentration caused a marked suppression of palmitate (16:0) flux in lean women, but the flux remained substantial in obese women despite greater plasma insulin concentrations (Jensen et al. 1989). Moreover, the rate of lipolysis of stored fat and the rate of appearance of plasma fatty acids depend on the plasma glucose and insulin concentrations, but the relationship between insulin sensitivity and plasma 
(a) Day1

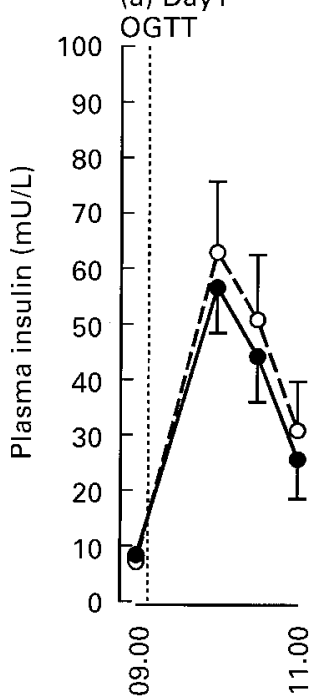

(b) Day 29

Meal

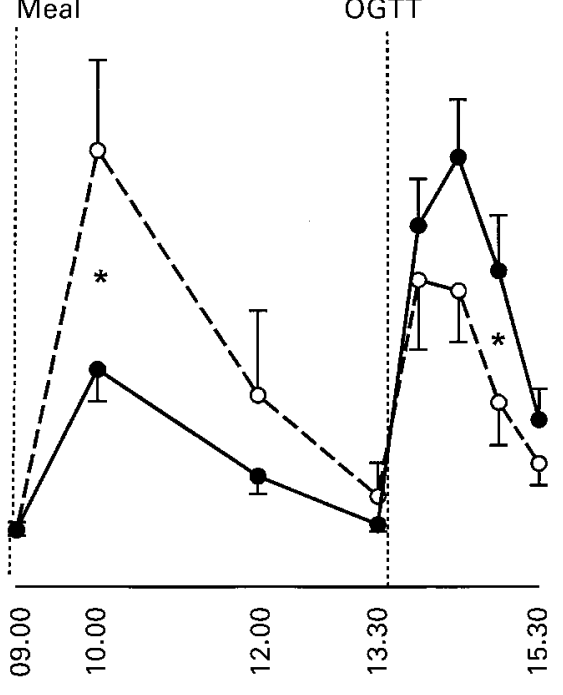

Time of day (hours)

Fig. 3. Plasma insulin concentration $(\mathrm{mU} / \mathrm{l})$ in healthy middle-aged men before (day 1 ; a) and after (day 29; b) consuming a low-fat $(\mathrm{L} ; \mathrm{O}$ ) or moderate-fat $(\mathrm{M}$; $)$ breakfast meal for $28 \mathrm{~d}$. Fasting insulin levels are shown at 09.00 hours on both days. An oral glucose dose was given at 09.00 hours on day 1 and at 13.30 hours on day 29. The breakfast meal was consumed at 09.00 hours on day 29. For details of the breakfast meals and procedures, see Table 2 and p. 738. Values are means with their standard errors represented by vertical bars for twelve subjects. ANOVA of $\log _{\mathrm{e}}$ transformed values showed significant differences between treatments on day 29 from 09.00 to 13.30 hours and from 13.30 to 15.30 hours $(P=$ 0.05 ). Mean values were significantly different between treatments within times: ${ }^{\star} P<0.05$. OGTT, oral glucose tolerance test.

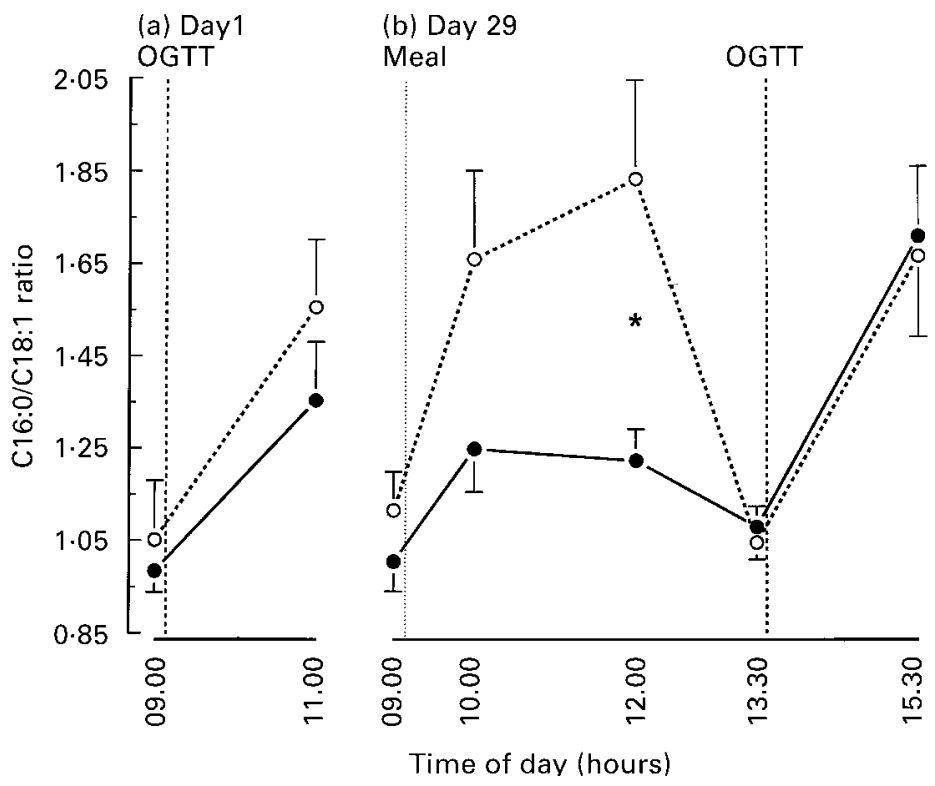

Fig. 4. Plasma non-esterified fatty acid ratios, $16: 0 / 18: 0(\mu \mathrm{g} / \mu \mathrm{g})$, in healthy middle-aged men before (day 1 ; a) and after (day 29; b) consuming a low-fat $(\mathrm{L} ; \mathrm{O})$ or moderate-fat $(\mathrm{M}$; $\bullet$ ) breakfast meal for $28 \mathrm{~d}$. Fasting ratios are shown at 09.00 hours on both days. An oral glucose dose was given at 09.00 hours on day 1 and at 13.30 hours on day 29. The breakfast meal was consumed at 09.00 hours on day 29. For details of the breakfast meals and procedures, see Table 2 and p. 738 . Values are means with their standard errors represented by vertical bars for twelve subjects. ANOVA showed significant differences between treatments on day 29 from 09.00 to 13.30 hours $(P<0.01)$. Mean values were significantly different between treatments within times: ${ }^{\star} P<0.05$. OGTT, oral glucose tolerance test. 
NEFA concentration is more pronounced during the postprandial period than during fasting (Ferrannini et al. 1997). At plasma glucose and insulin concentrations of $7.2 \mathrm{mmol} / \mathrm{l}$ and $20-25 \mathrm{mU} / \mathrm{l}$ respectively, both lipolysis and the rate of appearance of plasma fatty acids were suppressed. However, when plasma glucose and insulin were held at $10.5 \mathrm{mmol} / \mathrm{l}$ and $40 \mathrm{mU} / \mathrm{l}$ respectively, the rate of appearance of plasma fatty acids was further suppressed (Wolfe \& Peters, 1987). Thus, postprandial intracellular fat mobilization rate depends on plasma insulin concentration and is suppressed to a lesser extent in obese and older subjects than in lean and younger subjects.

During the first 90 min of the OGTT the serum insulin exceeded $35 \mathrm{mU} / 1$ with both treatment groups on days 1 and 29. This response was associated, proportionately and between treatments, with similar increases in saturated fatty acids and decreases in monounsaturated fatty acids in the NEFA $(P<0.002)$. However, following consumption of the breakfast meals, the insulin response was elevated in both treatment groups, but was significantly higher for treatment $\mathrm{L}(P=0 \cdot 05)$. Over this meal period the fatty acids $16: 0$ and 18:1 contributed over $60 \mu \mathrm{g} / 100 \mu \mathrm{g}$ total measured plasma NEFA. 18:1 was significantly higher $(P<0 \cdot 01)$, whereas $16: 0$ was significantly lower $(P<0.05)$ for treatment $\mathrm{M}$ than treatment L (Fig. 1).

The mobilization of fatty acids by HSL in adipose tissue of laboratory animals is positively correlated with unsaturation (Raclot \& Groscolas, 1993; Connor et al. 1996). This observation is consistent with our evidence that a meal of carbohydrate should be closely associated with a decrease in the relative proportions of monounsaturated fatty acids and an increase in the relative proportions of saturated fatty acids in total NEFA.

As the proportions of saturated fatty acids relative to monounsaturated fatty acids in the NEFA differed between treatments following breakfast at 12.00 hours but not in the fasting plasma, an explanation was sought. Circulating 17:0 fatty acid was measured, as oddnumbered - $\mathrm{C}$ fatty acids are not synthesized endogenously and must be of dietary origin. Indeed, it has been proposed that 17:0 in subcutaneous adipose tissue (Wolk et al. 1998) and 15:0 in serum (Smedman et al. 1999) might be valid biological markers of long-term milk-fat intake. 17:0 was not detectable either in the evening meal for both treatment groups on day 28 or in the breakfast for treatment L on day 29. By contrast, the proportion of 17:0 in the NEFA was greater for treatment $\mathrm{L}$ than for treatment $\mathrm{M}$ at 12.00 hours on day $29(P=0.0055)$. This proportional response was consistent with that of other saturates, indicating suppression of intracellular fat mobilization. Consumption of 17:0 during days 2-28 was assessed blind from the individual food diaries. Dietary 17:0 was found to be positively correlated, within treatment, to plasma 17:0 ( $\mu \mathrm{g} / 100 \mu \mathrm{g}$ NEFA) when plasma insulin was at post-absorptive concentrations on day $29(r 0.46, P<0.05)$, indicating tissue storage as its source. These data support a conclusion that the raised total NEFA content of treatment $\mathrm{M}$ plasma $3 \mathrm{~h}$ after the meal was derived to a measurable extent from fatty acids mobilized in storage tissues.

\section{Associations amongst response characteristics}

Arner (1995) observed that the rate of lipolysis by HSL is low in the subcutaneous femoral and gluteal regions, intermediate in the subcutaneous abdominal region and high in the visceral (omental) region, and Coon et al. (1992) found a correlation between waist:hip circumference and the rate of decline of plasma NEFA concentration during euglycaemic hyperinsulinaemic clamping. Byrne $e t$ al. (1998) reported that fasting insulin levels and waist:hip circumference predicted percentage NEFA suppression in men. The negative correlations in the present study between fasting 16:0 and waist:hip circumference $(P=0.0009)$, and between 16:0 and contemporary $\log _{\mathrm{e}}$ insulin AUC $(P=0.0001)$ are consistent with this evidence, but not proof of cause and effect. A raised proportion of NEFA as 16:0 may reflect a suppression of endogenous fat mobilization. The mobilization of omental fat is resistant to suppression by raised postprandial plasma insulin, especially in subjects with a high waist:hip circumference.

\section{Conclusions}

The net outward flux of NEFA was greater, and its profile different, during the 1-3 h postprandial period for treatment $\mathrm{M}$ than for treatment $\mathrm{L}$. This difference occurred at a time when plasma insulin concentration was lower for treatment $\mathrm{M}$, but which greatly exceeded $13-16 \mathrm{mU} / \mathrm{l}$ in both groups. Thus, an adverse effect of a fatty meal on glucose tolerance and insulin function may be expressed by its failure to adequately inhibit intracellular fat mobilization.

It is concluded that a substantial rise in postprandial plasma insulin concentration is associated with a rise in the proportion of saturated fatty acids and a decrease in the proportion of monounsaturated fatty acids in plasma NEFA. This difference does not persist following a fatty meal amongst middle-aged men. It is proposed that the subjects who received a breakfast providing 26 , rather than $5 \mathrm{~g}$ fat, especially those with an excessive waist:hip circumference, may have been less able to suppress postprandial intracellular fat mobilization. They appear to have expressed insulin resistance, notably by a strong negative correlation between the postprandial plasma concentrations of the NEFA 16:0 and insulin. Insulin resistance and an excessive waist:hip circumference appear to be associated with elevated postprandial plasma NEFA that is relatively rich in monounsaturated fatty acids. These observations are in accordance with recent conclusions from a cross-sectional survey by Han et al. (1999) that type 2 diabetes is strongly associated with a high waist:hip circumference. Further investigation is required to clearly differentiate between rates of mobilization and clearance of postprandial NEFA in subjects receiving isoenergetic fatty and carbohydrate meals.

\section{Acknowledgements}

The authors would like to express their thanks to Dr B. W. Maitland and Dr A. N. Howard for support, to Mrs Judy West and Mr Christopher Marshall of Hinchingbrooke Hospital for technical assistance, to Ms Bridget K. Stein, 
Mr G. Llewelyn and Dr J. A. Ballantine of the National Mass Spectrometry Service Centre, Chemistry Department, University of Wales, Singleton Park, Swansea SA2 8PP, and to the volunteer subjects who participated in the study. The authors are also very grateful to The Kellogg Company of Great Britain Ltd for financial support.

\section{References}

Altman DG (1991) Practical Statistics for Medical Research. London: Chapman and Hall.

Arner P (1995) Differences in lipolysis between human subcutaneous and omental adipose tissues. Annals of Medicine 27, 435-438.

Arner P, Einarsson KES \& Livingstone J (1986) Studies of the human liver insulin receptor in non-insulin-dependent diabetes mellitus. Journal of Clinical Investigation 77, 1717-1718.

Bligh EG \& Dyer WJA (1959) A rapid method of total lipid extraction and purification. Canadian Journal of Biochemistry and Physiology 37, 911-917.

Brook CGD (1971) Composition of human adipose tissue from deep and subcutaneous sites. British Journal of Nutrition 25, 377-380.

Byrne CD, Maison P, Halsall D, Martensz N, Hales CN \& Wareham NJ (1998) Factors predicting capacity to suppress plasma non esterified fatty acid levels differ between men and women. Atherosclerosis 141, 186.

Connor WE, Lin DS \& Colvis C (1996) Differential mobilization of fatty acids from adipose tissue. Journal of Lipid Research 37 , 290-298.

Coon PJ, Rogus EM \& Goldberg AP (1992) Time course of plasma free fatty acid concentration in response to insulin: effect of obesity and physical fitness. Metabolism 41, 711-716.

Ferrannini E, Camastra S, Coppack SW, Fliser D, Golay A \& Mitrakou A (1997) Insulin action and non-esterified fatty acids. Proceedings of the Nutrition Society 56, 753-761.

Fielding BA \& Frayn KN (1998) Lipoprotein lipase and the disposition of dietary fatty acids. British Journal of Nutrition 80, 495-502.

Frape DL, Williams NR, Rajput-Williams J, Maitland BW, Scriven AJ, Palmer CR \& Fletcher RJ (1998) Effect of breakfast fat content on glucose tolerance and risk factors of atherosclerosis and thrombosis. British Journal of Nutrition $\mathbf{8 0}$, 323-331.

Frape DL, Williams NR, Scriven AJ, Palmer C, O'Sullivan K \& Fletcher RJ (1997) The effects of high- and low-fat meals on the diurnal response of plasma lipid metabolite concentrations in healthy middle-aged volunteers. British Journal of Nutrition 77, 375-390.

Frayn KN (1993) Insulin resistance and lipid metabolism. Current Opinion in Lipidology 4, 197-204.

Frayn KN, Summers LKM \& Fielding BA (1997) Regulation of plasma non-esterified fatty acid concentration in the postprandial state. Proceedings of the Nutrition Society 56, 713-721.

Friderickson DS \& Gordon RS Jr (1958a) Transport of fatty acids. Physiological Reviews 38, 602-604.
Friderickson DS \& Gordon RS Jr (1958b) The metabolism of albumin-bound C14-labeled unesterified fatty acids in normal human subjects. Journal of Clinical Investigation 37, 15041514.

Griffiths AJ, Humphreys SM, Clark ML, Fielding BA \& Frayn KN (1994) Immediate metabolic availability of dietary fat in combination with carbohydrate. American Journal of Clinical Nutrition 59, 53-59.

Han TS, Feskens EJM, Lean MEJ \& Seidell JC (1999) Associations of body composition with Type 2 diabetes mellitus. Diabetic Medicine 15, 129-135.

Heffernan AGA (1963) The fatty acid composition of human adipose tissue. Clinical Science 25, 423-429.

Jensen MD, Haymond MW, Rizza RA, Cryer PE \& Miles JM (1989) Influence of body fat distribution on free fatty acid metabolism in obesity. Journal of Clinical Investigation 83, $1168-1173$.

Jones AE, Stolinski M, Smith RD, Murphy JL \& Wootton SA (1999) Effect of fatty acid chain length and saturation on gastrointestinal handling and metabolic disposal of dietary fatty acids in women. British Journal of Nutrition 81, 37-43.

Kokatnur MG, Oalmann MC, Johnson WD, Malcom GT \& Strong JP (1979) Fatty acid composition of human adipose tissue from two anatomical sites in a biracial community. American Journal of Clinical Nutrition 32, 2198-2205.

Malcom GT, Bhattacharyya AK, Velez-Duran M, Guzman MA, Oalmann MC \& Strong JP (1989) Fatty acid composition of adipose tissue in humans: differences between subcutaneous sites. American Journal of Clinical Nutrition 50, 288-291.

Medina I, Auborg S, Gallardo JM \& Perez-Martin R (1992) Comparison of six methylation methods for analysis of the fatty acid composition of albacore lipid. International Journal of Food Science and Technology 27, 597-601.

Pittet PG, Halliday D \& Bateman PE (1979) Site differences in the fatty acid composition of subcutaneous adipose tissue of obese women. British Journal of Nutrition 42, 57-61.

Raclot T \& Groscolas R (1993) Differential mobilization of white adipose tissue fatty acids according to chain length, unsaturation and positional isomerism. Journal of Lipid Research 34, $1515-1526$.

Smedman AEM, Gustafsson I-B, Berglund LGT \& Vessby BOH (1999) Pentadecanoic acid in serum as a marker for intake of milk fat: relations between intake of milk fat and metabolic risk factors. American Journal of Clinical Nutrition 69, 22-29.

Svedberg J, Björntorp P, Smith U \& Lönnroth P (1990) Free-fatty acid inhibition of insulin binding, degradation, and action in isolated rat hepatocytes. Diabetes 39, 570-574.

Wolfe RR (1998) Metabolic interactions between glucose and fatty acids in humans. American Journal of Clinical Nutrition 67, Suppl. 3, 519S-526S.

Wolfe RR \& Peters EJ (1987) Lipolytic response to glucose infusion in human subjects. American Journal of Physiology 252, E218-E223.

Wolk A, Vessby B, Ljung H \& Barrefors P (1998) Evaluation of a biological marker of dairy fat intake. American Journal of Clinical Nutrition 68, 291-295. 